\title{
International X-ray Analysis Society (IXAS) forms in Barcelona
}

A new type of scientific society focused on the use of $X$-ray neutrons and electrons in materials characterization has been established. This fully electronic nonprofit society will have free, open membership to the world's community of X-ray analysts requiring only that they have access to the World Wide Web. The purpose of the Society is to serve professionals working in the field of materials analysis by: (a) fostering interaction among materials scientists, chemists, physicists, geologists, and others engaged in the use of $\mathrm{X}$-rays and other radiations, including neutrons and electrons, for materials analysis; (b) sponsoring meetings of interest to those in the field of materials analysis; and (c) disseminating information of interest to the materials analysis community.

The Society will provide the following services to its members at no cost to them:

1. Support network of Materials Analysts via e-discussion groups

2. Job Clearinghouse- post your job notice or your resume free

3. Future Meetings Bulletin board

4. Analysis Problems Bulletin board-ask the experts about your problem

5. Newsletter to be e-mailed containing articles of general interest, news of IXAS, news of people, news of companies, meetings reports, future meetings, future workshops, courses on X-ray analysis, with translation to many languages by volunteer members

6. X-ray Analysis Meetings Proceedings and abstracts on web

7. Fully electronic Journal JXA on the web and free to all

8. Data committee: XRF fundamental parameters on the web.

In addition other activities like the development of "Best Practices", procedures for analysis, etc., will become part of the Society's work in the years to come.

An international steering committee ${ }^{\mathrm{a}}$ met in conjunction with the Seventh European Powder Diffraction Conference in Barcelona on 20 May 2000 and completed the formal establishment of IXAS. The society is now incorporated and the first five of the fifteen-member board of councilors has been elected. R. L. Snyder will serve as the first President, with G. McCarthy as Treasurer, Peter Wobrauschek, Secretary, and Hideo Toraya and Rene Ván Grieken as the first two councilors-at-large. The Nominating Committee composed of D. Taylor (U.K.), Chair; V. Buhrke (USA), H. Goebel (Germany), H. Gohshi (Japan), and T. Huang (USA/ Taiwan) will propose candidates for a vice president and four more councilors for election in August 2000 at the Denver $\mathrm{X}$-ray Conference. The final four councilors and next year's vice president will be elected in the first society-wide election in the Spring of 2001.
The Society is modeled along the lines of the "dot com" web companies like Yahoo that pay for the services provided to members via advertising. This new "dot org" society will use the income from its sponsors to provide the services listed above as more traditional societies do from the dues of the membership. Officers and editors of the nonprofit society will serve as volunteers as is done in traditional societies. The Membership Committee, composed of $\mathbf{M}$. Delgado (Venezuela), Chair; B. Holynska (Poland), and S. F. Lin (China), is to define the membership web form and establish any other procedures relating to the maintenance and use of the membership roster.

A Publications Committee composed of P. Scardi (Italy), Chair; T. Huang (USA/Taiwan), and R. Van Grieken (Belgium) will work to establish the guidelines for the operation of the Journal of X-ray Analysis (JXA) as a fully electronic journal with free access to the world community. In addition, they will work to establish the relationships with the world's analysis conference to arrange for the publication of their abstracts and proceedings on the web also available to all.

Under these conditions the Society hopes to electronically bring together the complete world community of materials characterization scientists using the techniques of X-ray, neutron and electron diffraction, spectroscopy, and absorption. To qualify for membership a person must state that they are personally engaged in the use or study of X-ray neutron or electrons for analysis. The only responsibilities of membership are to vote in the annual election, which will generate the next year's membership list, and the granting of permission to receive e-mail from IXAS and its sponsors.

The founding sponsor of IXAS is the International Centre for Diffraction Data which provided the funds to the Denver Conference Organizing Committee to establish the International Steering Committee ${ }^{\mathrm{a}}$ which has met once in Frankfurt and again in Barcelona to complete their task of incorporating and defining the bylaws of the Society. The EPDIC steering committee has appointed Eric Mittemeijer as a representative to the IXAS council and the IUCr's Commission on Powder Diffraction has also agreed to name a representative to council. The first version of our web site is available at www.ixas.org where the community is urged to join.

${ }^{\text {a}}$ Robert L. Snyder, Chair, USA

Paolo Scardi, Vice-Chairman, Italy

Peter Wobrauschek, Secretary, Austria

Gregory McCarthy, Treasurer, USA

Eugene Antipov, Russia

Miguel Delgado, Venezuela

Yohichi Gohshi, Japan

Herbert Goebel, Germany

Rod Hill, Australia

Barbara Holynska, Poland

Shao-Fan Lin, China

Brian O'Connor, Australia 
Randolph Barton, USA

Vic Buhrke, USA

John Gilfrich, USA

George Havrilla, USA

Ting Huang, USA/Taiwan

David Taylor, U.K.

Hideo Toraya, Japan

Vaclav Valvoda, Czech Republic

Rene Van Grieken, Belgium

Ron Jenkins, USA

Cev Noyan, USA

Paul Predecki, USA

Deane Smith, USA

Mary Ann Zaitz, USA
And a note from the editor:

The above editorial was prepared by Professor Robert $\mathrm{L}$. Snyder. He is the first President of IXAS and the Chairman of the Department of Materials Science and Engineering at Ohio State University. A Fellow of the American Ceramic Society, Professor Snyder is the author of three books and more than 200 published papers. He is active in numerous professional organizations and served as Chairman of ICDD from 1996 to 2000.
Ting C. Huang Editor-in-Chief 